Research Article

\title{
Research on Financing of Small and Micro Enterprises in Postepidemic Period: Based on Evolutionary Game and Numerical Simulation
}

\author{
Yun $\mathrm{Xu}^{1}$ and Quan Liu $\mathbb{D}^{2}$ \\ ${ }^{1}$ Ningbo University of Finance \& Economics, Ningbo 315175, China \\ ${ }^{2}$ Agricultural Bank of China Ningbo Branch, Ningbo 315000, China \\ Correspondence should be addressed to Quan Liu; 1548575548@qq.com
}

Received 5 July 2020; Revised 25 August 2020; Accepted 25 September 2020; Published 3 March 2021

Academic Editor: Yumin Cheng

Copyright (c) 2021 Yun Xu and Quan Liu. This is an open access article distributed under the Creative Commons Attribution License, which permits unrestricted use, distribution, and reproduction in any medium, provided the original work is properly cited.

\begin{abstract}
Small and microenterprises are most affected during the COVID-19 epidemic period. Despite the government introducing many preferential policies, financing for small and microenterprises is still difficult. Based on evolutionary game theory and Matlab r2017b software, this paper discusses the causes of financing problems from two aspects. By taking loan amount, loan interest rate, guarantee value, and intermediary business income as variables, the research shows that banks not only pay attention to the comprehensive return of small and microenterprises but also pay more attention to the coverage of loan principal and interest by the value of collateral. Relying on collateral for credit is still the main way, and the lack of collateral causes financing difficulties of small and microenterprises. Accordingly, this paper puts forward the countermeasures and suggestions to improve the guarantee compensation mechanism and innovate the financing mode.
\end{abstract}

\section{Introduction}

Small and microenterprises have small production scale, weak antirisk ability, and small adverse changes in the macro environment may have a fatal impact on them [1]. Once there is a shortage of funds, it is easy to break the capital chain or even go bankrupt [2]. Under the normal business environment, small and microenterprises are facing the problem of financing difficulty and high financing [3-5]. During the epidemic period, financial support is more needed, but it is more difficult to obtain [6]. The impact of the epidemic on most small and microenterprises is concentrated in the waste of shutdown capital, the difficulty in implementing marketing plans, the impact of transportation and logistics, and the decline of product demand. Small and microenterprises have different degrees of pressure on shortterm debt repayment and employee wage payment [7]. Some even face comprehensive losses, but they still insist on operation, and the large capital gap produces a large amount of financing demand. Small and microenterprises have low credibility and unstable repayment sources and lack collateral, and the probability of overdue or even nonperforming loans is high [8]. The grassroots credit officers also need to bear the corresponding responsibilities, which makes the financing difficult. In order to solve the financing problem of small and microenterprises during the epidemic period, the decision-making level has repeatedly tilted the policy, requiring banks to make profits to small and microenterprises, such as targeted reduction of the reserve requirement by 0.5 to 1 percentage point, increasing the amount of refinancing by 1 trillion yuan, and issuing 300 billion yuan of small and micro financial bonds [9]. However, the short-term effect of the policy is difficult to form a long-term risk compensation mechanism. Under the normalization of epidemic prevention and control, on the one hand, banks bear high risks; on the other hand, the corresponding risk compensation mechanism cannot keep up with it. The promotion of dual factors aggravates the 
phenomenon of "cautious lending" and "fear of lending," which makes it difficult to break the existing equilibrium.

The current social moral and legal restraint mechanism is not perfect, and the punishment measures about social subject dishonesty are not strict [10]. As a result, the cost of enterprise default is too low, and the phenomenon of debt evasion often occurs [11]. Due to the extremely asymmetric information between banks and enterprises, it is difficult for banks to accurately judge the credit status, real operation, and capital flow of small and microenterprises [12]. Many small and microenterprises had difficulties in turnover before the outbreak of the epidemic and could not resume normal operation after obtaining loans. Instead, they transferred assets, emptied enterprises, and defaulted on bank loans on the grounds of insufficient funds and bankruptcy. It is still limited for banks to clear and resolve nonperforming loans, which leads to partial or total loss of loan principal and interest. In particular, since the outbreak of the epidemic, the downward pressure of macro economy has been great. There are more small and microenterprises in arrears with bank loans, even some of which refuse to repay on the ground of being affected by the epidemic situation. The pressure on the trial and execution of bank cases has brought great difficulties to the resolution of nonperforming loans.

Banks and small and microenterprises are the research objects of this paper. The loan amount, loan interest rate, guarantee value, and intermediary business income are the research variables. Evolutionary game and Matlab simulation are the research methods. The purpose of this paper is to analyze the change trend of strategy selection about bank and enterprise dynamically and study the premise conditions and stability of the optimal combination (banks choose loans, enterprises choose repayment). We hope to provide path selection and guidance suggestions for the financing of small and microenterprises in the postepidemic period.

\section{Variable Hypothesis and Model Construction}

At present, the information transparency and guarantee degree of small and microenterprises are relatively low. It is difficult for banks to grasp the true and comprehensive information, they and cannot accurately judge the extent of enterprises affected by the epidemic situation and the current operation status. Under such asymmetric information, banks will face certain moral hazard as capital suppliers. Some small and microenterprises maliciously evade debts after obtaining loans, resulting in losses of bank principal and interest. In this case, banks may ask enterprises to add additional guarantee, which in turn forms a reverse restriction on the default of enterprises. The specific mechanism of action will be discussed in the following study in detail.

The two main players of the game are banks and small and microenterprises. The strategic space of banks is (loan, no loan), and the strategic space of enterprises is (repayment, nonrepayment). The strategic combination of banks and enterprises is (loan, repayment), (loan, no repayment), (no loan, repayment), and (no loan, no repayment). Among them, the probability of banks choosing loans is " $x$," the probability of not lending is " $1-x$ " $(0 \leq x \leq 1)$, the probability of enterprises choosing repayment is " $y$," and the probability of nonrepayment is " $1-y$ " $(0 \leq y \leq 1)$.

(1) " $p$ " is the loan principal, which is determined by the bank according to the actual operation of small and microenterprises, the use of funds, and guarantee measures.

(2) " $r$ " is the loan interest rate, which is reasonably determined by the bank according to the credit of small and microenterprises, loan risk, business cost, comprehensive income, interbank level, and other factors.

(3) " $R$ " is the expected rate of return of small and microenterprises, which depends on the use of funds and profitability of enterprises. Assume that the premise of debt financing is satisfied, that is, " $R>r$."

(4) " $g$ " is the value of collateral provided by small and microenterprises for loans. The guarantee methods include mortgage, pledge, and guarantee. When the loan cannot be repaid at maturity, the proceeds will be paid to the bank by auction.

(5) " $\pi$ " represents the intermediate business income of the bank, which is generated by a large number of enterprise settlement in the bank. If " $\pi$ " is greater than 0 , the income of intermediate business is positive; if " $\pi$ " is less than 0 , it is negative.

It can be seen from the above variable hypothesis that when the bank chooses to lend to the enterprise and the enterprise finally chooses to repay, the bank not only obtains the interest income "pr" but also obtains the intermediary business income " $\pi$ "; " $p r+\pi$ " reflects the comprehensive return level of small and microenterprises to banks. After deducting bank interest, the expected earnings of enterprises using loans is " $p(R-r)$ "; when the bank chooses to lend to the enterprise and the enterprise finally chooses not to repay, the loan principal and interest loss of the bank is " $p(1+r)$," and the compensation obtained by means of collateral disposal is " $g$." When the enterprise does not repay the bank loan, the principal " $p$ " does not need to be repaid. In addition, the operating income earned by using the principal " $p$ " is " $p R$," but the loss caused by the disposal of mortgage and pledge is " $g$ ". When the bank chooses not to loan and the enterprise has the ability to repay, the bank's income is 0 , and the enterprise's loss caused by capital shortage is " $p(R-r)$ ". When the bank chooses not to loan and the enterprise chooses not to repay, the income of both banks and enterprises is 0 . The evolutionary game matrix of both sides is shown in Table 1.

The income of bank's choice of loan, nonloan, and expected return is as follows: 
TABle 1: Game matrix between banks and enterprises.

\begin{tabular}{cccc}
\hline & & \multicolumn{2}{c}{ Small and microenterprises } \\
& & Repayment $(y)$ & Nonrepayment $(1-y)$ \\
\hline \multirow{3}{*}{ Bank } & $\begin{array}{c}\text { Loan }(x) \\
\text { No loans } \\
(1-x)\end{array}$ & $p r+\pi, p(R-r)$ & $g-p(1+r), p(1+R)-g$ \\
& $0,-p(R-r)$ & 0,0 \\
\hline
\end{tabular}

$$
\begin{aligned}
& u_{1}=y(p r+\pi)+(1-y)(g-p-p r) \\
& u_{1}^{\prime}=y^{*} 0+(1-y)^{*} 0 \\
& \bar{u}_{1}=x u_{1}+(1-x) u_{1}^{\prime} .
\end{aligned}
$$

The income of enterprise's choice of repayment, the income of nonrepayment, and the expected income are as follows:

$$
\begin{aligned}
& u_{2}=x[p(R-r)]+(1-x)[-p(R-r)], \\
& u_{2}^{\prime}=x[p(1+R)-g]+(1-x)^{*} 0, \\
& \bar{u}_{2}=y u_{2}+(1-y) u_{2}^{\prime} .
\end{aligned}
$$

According to the replication dynamic equation of evolutionary game, the proportion change speed of strategy choice of banks and enterprises is as follows [13]:

$$
\begin{aligned}
& J=\left(\begin{array}{cc}
\frac{\partial F(x)}{\partial x} & \frac{\partial F(x)}{\partial y} \\
\frac{\partial F(y)}{\partial x} & \frac{\partial F(y)}{\partial y}
\end{array}\right) \\
& =\left(\begin{array}{c}
(1-2 x)[y(p+2 p r+\pi-g)-(p+p r-g)] \\
y(1-y)[g-p(1+r)+p(R-r)]
\end{array}\right.
\end{aligned}
$$

When the condition " $R>r$ " is satisfied, according to the value symbols of $p r+\pi, g-p(1+r)$, det $J$, and $t r J$, the local stability of the above equilibrium points is obtained, as shown in Table 2.

According to Table 2, the evolutionary game path of banks and enterprises under corresponding conditions is shown in Figures 1(a)-1(c).

Conclusion 1. When the condition " $p r+\pi>0, g>p(1+r)$ " is satisfied, it can be seen from Figure 1(a) that the sum of interest income and intermediary business income (comprehensive return) after bank lending is greater than 0 , and the value of disposed mortgage and pledge after default is greater than the sum of loan principal and interest. In addition to the interest and medium income, banks also have a second source of repayment with sufficient value to guarantee the risk. The probability " $x$ " of bank lending presents an increasing trend and finally tends to 1 (lending). If the enterprise chooses to default, the principal and interest of the loan will not be repaid, but the value of the disposed mortgage is greater than the sum of the loan principal and

$$
\begin{aligned}
F(x) & =\frac{\mathrm{d} x}{\mathrm{~d} t}=x\left(u_{1}-\bar{u}_{1}\right)=x(1-x)\left(u_{1}-u_{1}^{\prime}\right) \\
& =x(1-x)[y(p+2 p r+\pi-g)-(p+p r-g)], \\
F(y) & =\frac{\mathrm{d} y}{\mathrm{~d} t}=y\left(u_{2}-\bar{u}_{2}\right)=y(1-y)\left(u_{2}-u_{2}^{\prime}\right) \\
& =y(1-y)\{x[g-p(1+r)+p(R-r)]-p(R-r)\} .
\end{aligned}
$$

Make $F(x)$ equal 0 and $F(y)$ equal 0 to get five equilibrium points $(0,0),(1,0),(0,1),(1,1)$, and $(((p(R-r)) /$ $(g-p(1+r)+p(R-r))),((p(1+r)-g) /(p+2 p r+\pi-g)))$.

\section{Stability Analysis of Equilibrium in Evolutionary Game}

According to Friedman's method [14], the stability of equilibrium point in differential system can be obtained by local stability analysis of Jacobian matrix, and the partial derivatives of $F(x)$ and $F(y)$ with respect to $x$ and $y$ are obtained:

$\left.\begin{array}{c}x(1-x)(p+2 p r+\pi-g) \\ (1-2 y)\{x[g-p(1+r)+p(R-r)]-p(R-r)\}\end{array}\right)$.

interest, resulting in a greater loss of nonrepayment of the loan. After repeated games between banks and enterprises, the probability combination $(x, y)$ eventually converges to $(1$, 1) point, realizing the stable equilibrium of bank loans and enterprise repayment.

Conclusion 2. When the condition " $p r+\pi>0, g<p(1+r)$ " is satisfied, it can be seen from Figure 1(b) that the sum of interest income and intermediary business income (comprehensive return) after bank lending is greater than 0 , and the value of disposed mortgage and pledge after enterprise's default is less than the sum of loan principal and interest. Although the sum of loan interest and intermediate income obtained by the bank is greater than 0 , the value of mortgage and pledge is not enough to cover the loan principal and interest, and the bank bears greater risk. Therefore, the probability " $x$ " of bank lending increases first and then decreases and finally tends to 0 (no loan). If the enterprise chooses to default, the loan principal and interest do not need to be repaid, and the value of the collateral is less than the loan principal and interest; even if the collateral is 
TABLE 2: Local stability of equilibrium point of game between banks and enterprises.

\begin{tabular}{lcccccccccccc}
\hline \multirow{2}{*}{ Stable point } & \multicolumn{3}{c}{$p r+\pi>0, g>p(1+r)$} & \multicolumn{3}{c}{$p r+\pi>0, g<p(1+r)$} & \multicolumn{3}{c}{$p r+\pi<0, g>p(1+r)$} & \multicolumn{3}{c}{$p r+\pi<0, g<p(1+r)$} \\
& $\operatorname{det} J$ & $\operatorname{tr} J$ & Stability & $\operatorname{det} J$ & $\operatorname{tr} J$ & Stability & $\operatorname{det} J$ & $\operatorname{tr} J$ & Stability & $\operatorname{det} J$ & $t r J$ & Stability \\
\hline$(0,0)$ & - & $N$ & Saddle point & + & - & ESS & - & $N$ & Saddle point & + & - \\
$(1,0)$ & - & $N$ & Saddle point & - & $N$ & Saddle point & - & $N$ & Saddle point & - & $N$ & Saddle point \\
$(0,1)$ & + & + & Instable & + & + & Instable & - & $N$ & Saddle point & - & $N$ & Saddle point \\
$(1,1)$ & + & - & ESS & - & $N$ & Saddle point & - & $N$ & Saddle point & + & + & Instable \\
\hline
\end{tabular}

Note. " $N$ " indicates that the value symbol is uncertain.

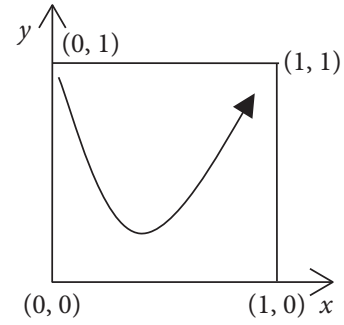

(a)

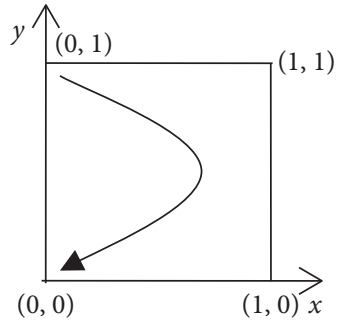

(b)

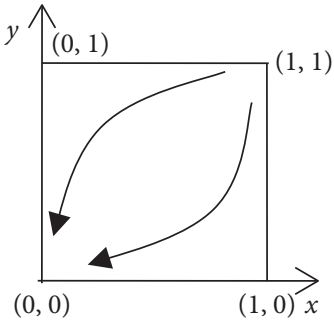

(c)

FIGURE 1: Evolutionary game path of banks and enterprises. (a) $p r+\pi>0, g>p(1+r)$. (b) $p r+\pi>0, g<p(1+r)$. (c) $p r+\pi<0, g<$ $p(1+r)$.

disposed of, the enterprise still benefits from the bank, and the repayment probability $y$ of the enterprise shows a decreasing trend and finally tends to 0 (no repayment). After repeated games, the probability combination $(x, y)$ finally converges to $(0,0)$ point and finally reaches the stable equilibrium of no lending by banks and no repayment by enterprises.

Conclusion 3. When the condition " $p r+\pi<0, g<p(1+r)$ " is satisfied, it can be seen from Figure 1(c) that the sum of interest income and intermediary business income (comprehensive return) after bank lending is less than 0 , and the value of disposed mortgage and pledge after enterprise's default is less than the sum of loan principal and interest. The bank cannot earn income from the enterprise's loan, and the value of the mortgage and pledge is not enough to cover the loan principal and interest, and the bank loan risk cannot be compensated. Therefore, the probability " $x$ " of bank lending presents a decreasing trend and finally tends to 0 (no loan). If the enterprise chooses to default, the loan principal and interest do not need to be repaid, and the value of the collateral is less than the loan principal and interest; even if the collateral is disposed of, the enterprise still benefits from the bank, and the repayment probability " $y$ " of the enterprise shows a decreasing trend and finally tends to 0 (no repayment). After repeated games, the probability combination $(x, y)$ finally converges to $(0,0)$ point and reaches the stable equilibrium of no lending by banks and no repayment by enterprises.

To sum up, when the expected operating rate of the enterprise is greater than the loan interest rate of the bank, the operating income of the enterprise still has a surplus after deducting the interest paid back to the bank. However, whether the bank loans to enterprises not only depends on the level of interest income but also on the profit and loss of intermediate income and on the value of collateral provided by enterprises. Considering that small and microenterprises lack collateral and often evade bank debt, banks are reluctant to lend to small and microbusinesses. Whether an enterprise is willing to repay the bank loan depends on the expected income generated by using the loan under a certain fund use and also depends on the value of the collateral provided by the enterprise to the bank. If the value of the collateral is greater than the principal and interest of the loan, the disposal of the collateral will cause more losses to the enterprise, and the default cost is too high, which forces the enterprise to repay the enterprise loan. It can be seen that full value and effective collateral can not only compensate the bank risk but also reverse restrict the default behavior of enterprises. However, a large number of small and microenterprises are small in scale and lack guarantee measures, and banks rely too much on the guarantee of collateral, resulting in financing difficulties of small and microenterprises, which have not been solved.

\section{Matlab Numerical Simulation}

In order to verify the local stability of each equilibrium point, the corresponding parameters are assigned to satisfy the equilibrium conditions of each game result, respectively, as shown in Table 3.

According to the parameter values in Table 3, the corresponding equalization results are simulated by Matlab r2017b software [15], which can verify the accuracy of the theoretical analysis. The $t$-axis coordinate of the following evolution chart represents the time change, which reflects the dynamic evolution process of the strategy selection of 
TABLE 3: List of parameter assignments.

\begin{tabular}{|c|c|c|c|c|c|}
\hline Equilibrium condition & $p$ & $r$ & $R$ & $g$ & $\pi$ \\
\hline$p r+\pi>0, g>p(1+r)$ & 100 & 0.05 & 0.1 & 150 & 1 \\
\hline$p r+\pi>0, g<p(1+r)$ & 100 & 0.05 & 0.1 & 70 & 1 \\
\hline$p r+\pi<0, g<p(1+r)$ & 100 & 0.05 & 0.1 & 70 & -10 \\
\hline
\end{tabular}

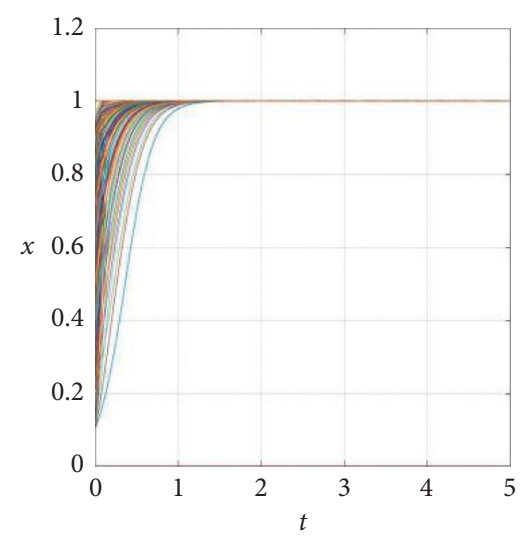

(a)

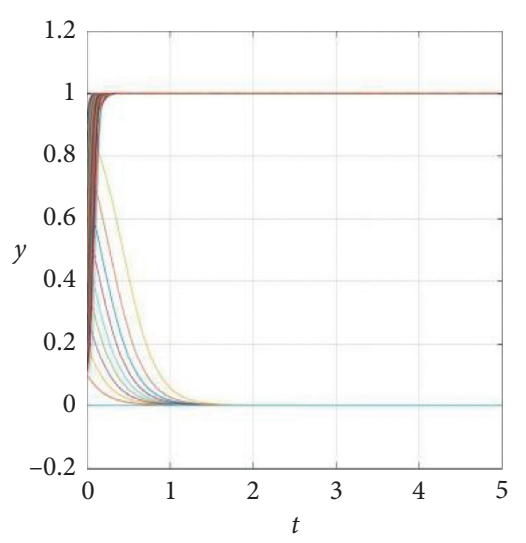

(b)

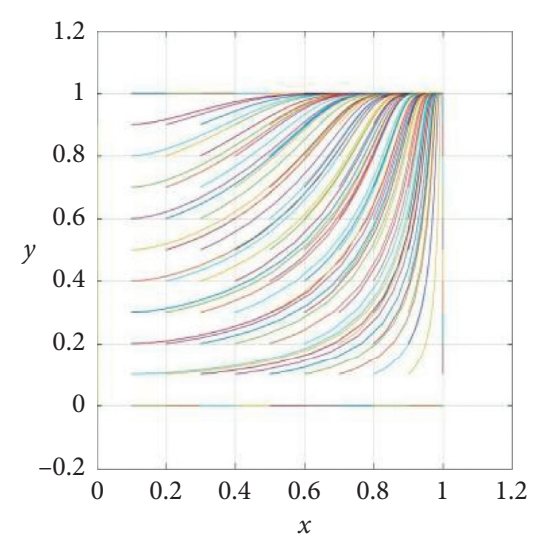

(c)

FIGURE 2: $p r+\pi>0, g>p(1+r)$. (a) The evolution graph of $X$. (b) The evolution graph of $Y$. (c) Path map of banks and enterprises.

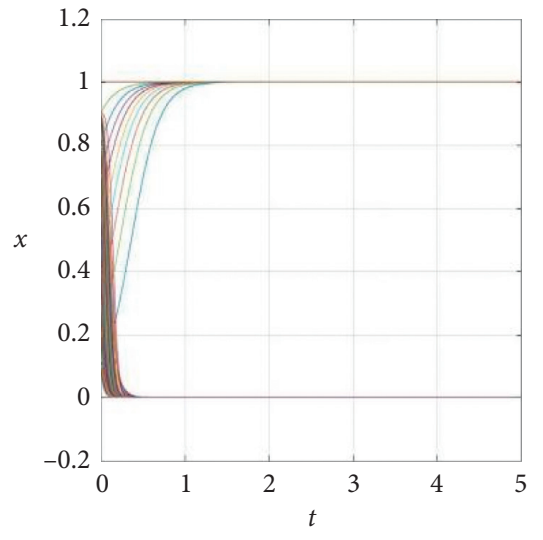

(a)

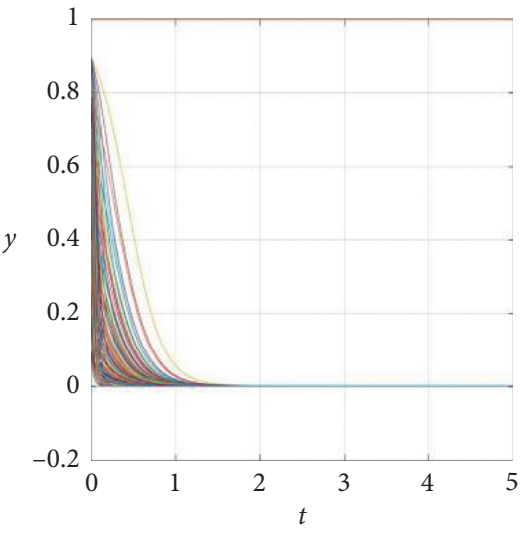

(b)

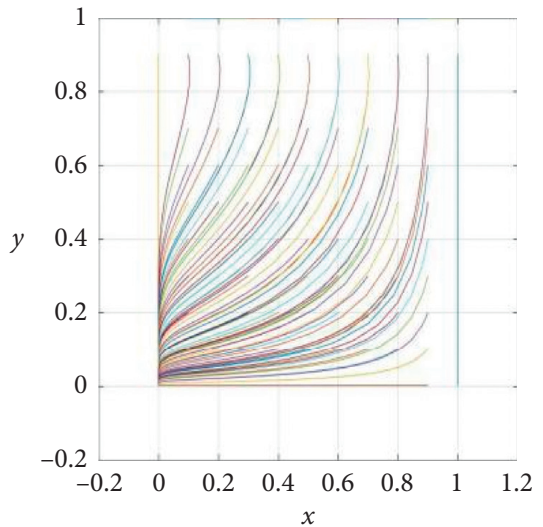

(c)

Figure 3: $p r+\pi>0, g<p(1+r)$. (a) The evolution graph of $X$. (b) The evolution graph of $Y$. (c) Path map of banks and enterprises.

both sides; the $x$-axis coordinate represents the probability of banks choosing loans, and the $y$-axis coordinate represents the probability of enterprises choosing repayment strategies. In order to ensure the objectivity of the simulation results, the probabilities " $x$ " and " $y$ " are continuously selected from 0 to 1 , and the evolutionary process of the game between banks and small and microenterprises is systematically and comprehensively simulated.

(1) When the condition " $p r+\pi>0, g>p(1+r)$ " is satisfied, the expected comprehensive return of bank loan is greater than 0 , and the sufficient collateral is provided by the enterprise. With the extension of time $t$, the probability " $X$ " of bank choosing loan tends to 1, as shown in Figure 2(a). Because the value of the collateral provided by the enterprise is higher than the principal and interest of the bank loan, the loss caused by the disposal of the collateral is relatively large after default. With the extension of time " $t$," the probability " $y$ " of choosing repayment tends to 1, as shown in Figure 2(b). After repeated games, the final probability combination $(x, y)$ reaches equilibrium at point $(1,1)$, as shown in Figure 2(c), which achieves a good financial situation of loan and repayment. The game result of Figure 1(a) is proved.

(2) When the condition " $p r+\pi>0, g<p(1+r)$ " is satisfied, the expected comprehensive return of bank loans is greater than 0 , and the value of collateral provided by small and microenterprises is 


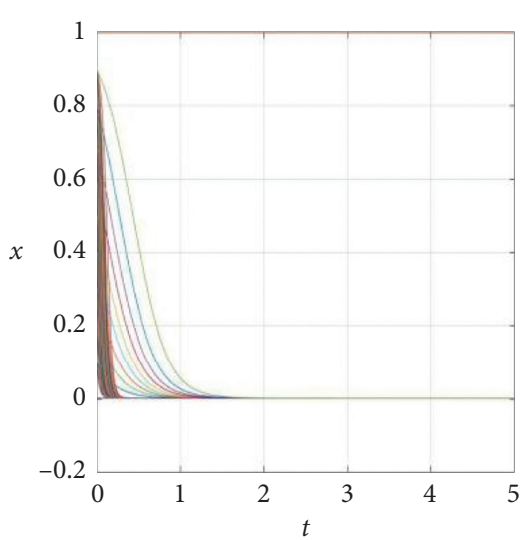

(a)

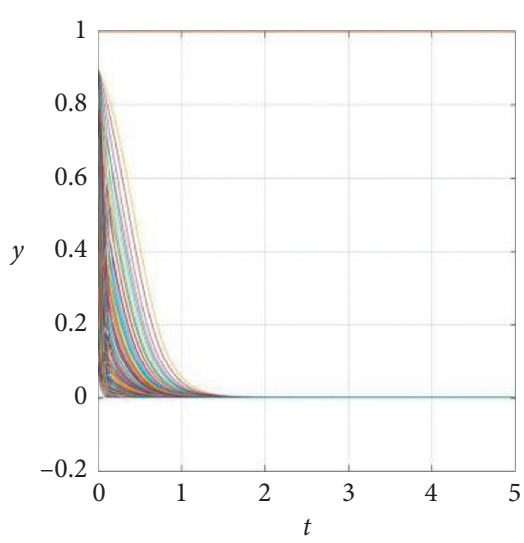

(b)

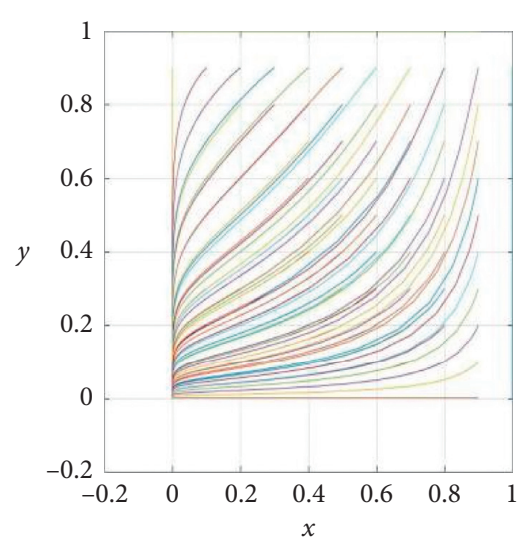

(c)

Figure 4: $p r+\pi<0, g<p(1+r)$. (a) The evolution graph of $X$. (b) The evolution graph of $Y$. (c) Path map of banks and enterprises.

insufficient to cover the loan principal and interest. Due to the information asymmetry between banks and enterprises, banks cannot fully grasp the credit situation of enterprises. In order to obtain comprehensive return, the probability $X$ of banks choosing loans gradually tends to 1 , as shown in Figure 3(a). Because the value of the collateral provided by the enterprise is lower than the loan principal and interest, the default cost is too low, small and microenterprises with poor credit are less likely to repay, and the probability $y$ eventually tends to 0 , as shown in Figure 3(b). In the process of game, the two sides of bounded rationality constantly speculate on the other party's intention. The bank's willingness to lend decreases with the increase of the possibility of enterprise's default. The final probability combination $(x, y)$ reaches equilibrium at $(0$, 0 ), as shown in Figure 3(c). Finally, the game result of Figure $1(\mathrm{~b})$ is proved.

(3) When the condition " $p r+\pi<0, g<p(1+r)$ " is satisfied, the expected comprehensive return of bank loans is less than 0 , the value of collateral is lower than the loan principal and interest, and the second source of repayment is insufficient, so the probability $X$ of banks choosing loans tends to 0 , as shown in Figure 4(a). Because the disposal of collateral cannot offset the loan principal and interest obtained by the enterprise and the default cost is too low, the probability $y$ of small and microenterprises with bad credit choosing to repay the loan eventually tends to 0 , as shown in Figure 4(b); the two sides constantly speculate about the other party's intention, and finally the small and microenterprises cannot obtain financing. The probability combination $(x, y)$ of both sides reaches equilibrium at $(0,0)$ point, as shown in Figure 4(c). Finally, banks do not choose to loan and enterprises do not choose to repay. The game result of Figure 1(c) is proved.

It can be seen that small and microenterprises cannot provide high-quality collateral, so it is difficult to form a full and effective loan credit enhancement. In addition, the "natural risk aversion" characteristic of banks' self-financing profit and loss aggravates the financing difficulties of small and microenterprises. In order to control the risk, banks are more willing to offer loans to enterprises with good loan returns and sufficient guarantee value. In response to the call of the government, banks have continued to increase loans to small and microenterprises. However, due to asymmetric information and the lack of collateral, banks' reluctance to lend to small and microenterprises cannot be completely solved, and the financing difficulty of small and microenterprises will exist for a long time.

\section{Countermeasures and Suggestions}

Small and microbusinesses are deteriorating during the COVID-19 epidemic period, and the credit risk of banks is increasing at the same time. From the game results and simulation results, we can see that it is still the main way to rely on collateral to provide credit. Banks not only pay attention to the comprehensive return of small and microenterprises' loan business but also pay more attention to the value of collateral, which may cover loan principal and interest. The lack of collateral leads to the "loaning fear" behavior of banks to small and microenterprises. To solve the financing problem of small and microenterprises thoroughly, the core is to establish a long-term risk compensation mechanism to reduce the dependence of banks on collateral. However, in the process of establishing a longterm mechanism, there are still some problems, such as asymmetric information between banks and enterprises, inadequate risk compensation mechanism, and poor social credit environment. Based on the above analysis, the countermeasures and suggestions are put forward as follows:

(1) Improve the risk compensation mechanism: at present, the bank credit risk control mode still relies on the second source of repayment guarantee, which is difficult to adapt to the financing needs of small and microenterprises without collateral. Banks should comprehensively use a variety of risk 
mitigation methods by establishing diversified cooperative relations with insurance, evaluation, credit investigation and collection, credit rating, credit guarantee, strength venture capital institutions, and other intermediaries. Banks can establish special funds for risk compensation by means of "bank + insurance," "venture capital + credit," and cooperation, and banks should give more play to the credit enhancement role of policy guarantee in the financing of small and microenterprises.

(2) Innovate financing mode of small and microenterprises: banks should make great efforts to promote supply chain financing business. Through the real transaction between the core enterprises and small and microenterprises on the upstream and downstream, the information transparency can be enhanced. Through the guarantee and credit enhancement measures provided by core enterprises, the lack of collateral of small and microenterprises can be solved. Through the strict access, restriction, and exit mechanism of core enterprises to small and microenterprises, the credit moral hazard can be reduced. Upstream small and microenterprises can borrow money from banks by pledge of accounts receivable from core enterprises. Downstream small and microenterprises sell products from core enterprises, and then they can use the funds as repayment sources to borrow money from banks. The risk sharing mechanism of supply chain can increase the default cost of small and microenterprises, and joint responsibility can reduce the amount of guarantee for small and microenterprises. Meeting the capital needs of small and microenterprises with light assets can enhance the "war epidemic" ability.

\section{Data Availability}

The data used to support the findings of this study are included within the article.

\section{Conflicts of Interest}

The authors declare that there are no conflicts of interest regarding the publication of this paper.

\section{References}

[1] J. W. Cheng, Z. G. Wang, and Z. G. Wang, "Research on the basic contradiction map and solution path of inclusive finance under the background of fin-tech of fin-tech," Financial Theory \& Practice, vol. 8, pp. 1-7, 2019.

[2] Y. S. Liu and C. Z. Tan, "Analysis of financing problems of small and microenterprises," Technology and Economic Guide, vol. 28, no. 12, pp. 187-188, 2020.

[3] Y. F. Lin and Y. J. Li, "Development of small and mediumsized financial institutions and financing of small and medium-sized enterprises," Economic Research, vol. 1, pp. 10-18, 2001.
[4] C. Liu, C. Liu, and G. R. Ma, "Small-and-medium banks and small-and-medium enterprise loans," Economic Research, vol. 52, no. 8, pp. 65-77, 2017.

[5] Y. Y. Ou and J. F. Li, "The evaluation of and policy recommendations about the support level for China's SME development," China Soft Science, vol. 10, pp. 142-147, 2009.

[6] W. X. Zhu, P. Zhang, P. F. Li, and Z. Y. Wang, "Firm crisis, government support and policy efficiency under the epidemic shock:evidence from two waves of questionnaire on SMEs," Management World, vol. 36, no. 4, pp. 13-26, 2020.

[7] S. S. Ba, "Policy suggestions on solving the financing problems of the small and micro businesses," Frontiers, vol. 12, pp. 22-30, 2020.

[8] Z. Wang and W. H. Chen, "Post epidemic period: further relief strategy for China's SMEs," Price Theory and Practice, vol. 4, pp. 8-11, 2020.

[9] D. S. Deng and Y. L. Zhao, "Difficulties and countermeasures of China's commercial banks supporting the development of small and microenterprises," Economic Review Journal, vol. 10, pp. 87-93, 2017.

[10] J. P. Han, D. D. Xu, and Y. Y. Guan, "Research on standardization of joint punishment for breach of credit," Credit Investigation, vol. 38, no. 3, pp. 11-17, 2020.

[11] H. An, "How to conduct post loan management of inclusive finance loan business," China Economist, vol. 7, pp. 115-116, 2020.

[12] Y. Q. Yang, "Research on financing of small and microenterprises," Co-Operative Economy \& Science, vol. 11, pp. 62-63, 2020.

[13] S. Y. Xie, "Evolutionary game theory under bounded rationality," Journal of Shanghai University of Finance and Economics, vol. 5, pp. 3-9, 2001.

[14] D. Friedman, "Evolutionary games in economics," Econometrica, vol. 59, no. 3, pp. 637-639, 1991.

[15] M. M. Wang, "Evolutionary game analysis of cooperation mechanism for collaborative product development in supply chain," Chinese Journal of Management Science, vol. 18, no. 6, pp. 155-162, 2010. 